\title{
Atmospheric Coalitions: Shifting the Middle in Late Industrial Baltimore
}

\author{
Chloe AhmanN \\ CORNELL UNIVERSITY
}

\begin{abstract}
STS scholars offer the atmosphere as an antidote to the homogenizing Anthropocene. They teach us that atmospheres are good to think because they are both diffuse and differential; they reflect the scale of planetary problems without forgetting that those problems manifest unevenly. The atmosphere has, then, become a useful tool for theory work. But it is also being picked up on the ground as a model for grassroots coalition building. This article follows one group we might call an atmospheric coalition, which coalesced to fight a trash incinerator proposed in south Baltimore City. That incinerator would have had a major impact on the local air, particularly due to heavymetal toxics that land close to their source. But it also would have affected a large regional airshed and released thousands of tons of greenhouse gases. Taking a cue from these multi-scalar impacts, the coalition to stop the incinerator both used the medium of air to trouble insider/outsider dichotomies and valued an uneven distribution of power, letting youth from the frontline community lead. Participants, in other words, built a flexible alliance-and they utilized its flexibility. Sometimes it was advantageous to call the incinerator "everyone's problem." Sometimes it was necessary to underscore its differential effects on local people. And sometimes the transience of atmospheric claims worked to transfer jurisdiction over the plant from one group to another. In the process of exploring these maneuvers, I argue that activists used the atmosphere to define a problem-space with pliant parameters of authority and vulnerability.
\end{abstract}

\section{Keywords}

atmosphere; problem-space; toxicity; climate change; social movements; jurisdiction; late industrialism; United States

\section{A Flexible Alliance}

Jack didn't like the premise of my question. "We're not outside...I don't think this is an inside/outside issue. The air-it's everyone's problem." We were sitting in a café in north Baltimore, not far from the building where Jack worked, and he was gesticulating wildly. His ruddy hands spun out from his body, performing the expansiveness of the whole thing. Then he

Chloe Ahmann, Email: chloeahmann@cornell.edu

Copyright (C) 2020 (Chloe Ahmann). Licensed under the Creative Commons Attribution Non-commercial No Derivatives (by-nc-nd). Available at estsjournal.org. 
snapped them back, barely avoiding his coffee. “So, when someone says, 'You're not from here,' they clearly haven't thought about the problem."

I had asked Jack how he and his colleagues at United Workers, a regional group headquartered a few blocks from our table, grappled with the charge that they were an "outside organization coming in" to a town nine miles south to "get everybody riled up." I had asked because it was an accusation I'd heard from many different people-state air-quality regulators, some long-time residents, a few of my professors-who questioned Jack's motives for fighting the Fairfield Renewable Energy Project.

If it were built, the Fairfield Project would have been the largest trash incinerator in the nation, burning 4,000 tons of waste each day to generate "clean" power in late industrial south Baltimore. It never was, so it's tough to speculate about its impact, but it was permitted to emit 240 pounds of mercury, 1,000 pounds of lead, and over 3,000 pounds of fine particulate matter each year, along with several hundred thousand metric tons of carbon. Slated for construction in a low-income, mixed-race neighborhood called Curtis Bay, the incinerator would have joined a crowded field of waste and energy projects, including several petrochemical factories, a massive coal-export terminal, a wastewater-treatment plant, a medical-waste incinerator, and a 150-acre city dump (Figure 1). It also would have affected residents, many living within a mile of the site, with a documented history of respiratory problems. ${ }^{2}$ But its emissions wouldn't stop at the neighborhood line. They "wouldn't care" if opponents lived in Curtis Bay or not. As far as Jack was concerned, any attempts to excise him from the zone of legitimate debate on the grounds of his "outsider" status were unthinking when it came to the geography of air pollution. Or-he flapped his hands again — those attempts were "just obstructionist."

Maybe. But the air was not the same in Curtis Bay, at least not on that unseasonably warm late April day. I had just come from there to meet Jack on the north side of the city. The air was heavy everywhere; Baltimore gets humid as the summer months sneak up. But in Curtis Bay it was so thick with particulates that it made me hyper-conscious of my breathing. The feeling took me back to days before graduate school, when I taught first grade in Curtis Bay. Come June, most kids would take breaks during recess. They'd rest their heads on their desks, they'd cough and recompose themselves, they'd describe the air as "sticky." It was the sort of heat that made six-year-olds elect to spend playtime indoors. And it was the sort of heat that I tried to clean off my body with Wet Ones on the 15-minute car ride north to Jack, but that I could still see clinging to my skin while we sipped coffee.

The thing is, Jack recognized these differences. In the same conversation, he noted Curtis Bay's history of respiratory disease. When he said the air was "everyone's problem," then, he didn't mean it affected everyone the same. Instead, what was so useful about the air for Jack was the concept's elasticity.

\footnotetext{
= According to the Environmental Integrity Project, locals are more likely than other Americans to die of heart disease, lung cancer, asthma, emphysema, chronic bronchitis, and COPD.
} 


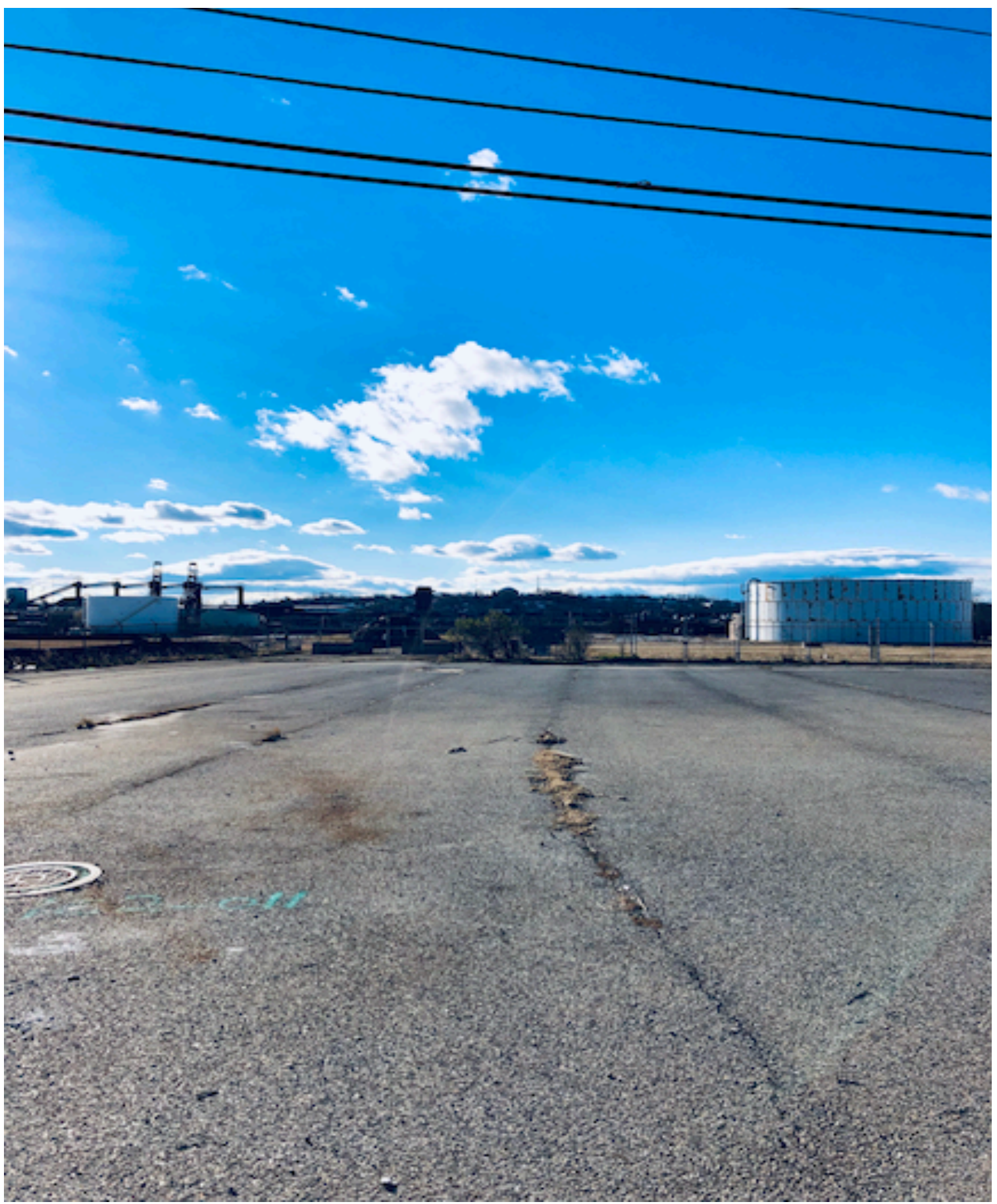

Figure 1: Planned site for the Fairfield Renewable Energy Project. Photo by the author, 2019. 
During the years I followed the campaign against the Fairfield Project-a campaign Jack worked with but did not lead-I noticed many actors invoke the atmosphere to negotiate the boundaries of their cause. It was around the same time STS and adjacent disciplines began to advocate for "atmospheric" thinking. The campaign began shortly after Timothy Choy wrote "air matters too little in social theory" (2011, 143). It reached its zenith the same year Cymene Howe (2015) invited scholars to take a cue from the air and theorize with a similar capacity for connection, grasping the atmosphere as object and method for a new kind of commoning. Let me be clear: I doubt Jack and his comrades were reading what I was reading, but there seemed to be an atmosphere of atmospherics afloat. Both in theory and in practice, people were looking to the sky for clues about how to think relationships between (and beyond) human beings.

In the humanistic social sciences, the atmosphere has taken hold among theorists hoping to disaggregate the Anthropocene. Atmospheres are good to think because they're both diffuse and differential. They reflect the scale of planetary problems without forgetting that those problems manifest unevenly. Atmospheres can "lift off, move, or settle" (Choy 2016), they can shapeshift, they can support temporary aggregations of "airy things" (Choy and Zee 2015). From studies of strange weather (Zee 2020), breath (Kenner Forthcoming; Vine 2019), and toxics (Sloterdijk 2009; Masco 2015; Shapiro 2015; Calvillo 2018; Blanchette 2019), to vivid conjurings of affect (McCormack 2008; Stewart 2011), scholars are turning to these mobile metaphors to capture how particulates travel across time and space, occasionally congealing into concrete forms (like dust storms and chemical clouds) that move people to do something.

But these forms are ephemeral and fluid. Just watch the sky on a windy day for evidence that atmospheres are multiple. No cloud is ever just one thing. As Timothy Choy and Jerry Zee remind, every gaseous mixture has a limited duration before its component parts disperse into new forms $(2015,213)$. For this reason, atmospheres are particularly well-suited to challenging old dualisms at the bedrock of modernist thought-including those like local/global, inside/outside, and nature/culture whose boundaries have failed in the late industrial period (Fortun 2014). In this article, I consider how atmospheres are also enabling political forms that can expand, constrict, and drift. By strategically invoking the air to shift the middle of a matter of concern, participants in these forms make tactical use of the medium's capricious qualities. Activists in Baltimore specifically seized on the atmosphere's material traits to proffer metaphors of connection and difference that, in turn, became power-sharing models. Along the way, they built what we might call an atmospheric coalition. In their deft hands, air appears to have a set of practical affordances that we have barely begun to grasp in social theory.

Between 2012 and 2016, I conducted 24 months of ethnographic fieldwork in Baltimore, working alongside participants from a dozen networked groups that comprised the coalition against the Fairfield Project. While this essay draws chiefly from my time in organizing spaces and my conversations (both structured and informal) with coalition members, I also spent time with resident-supporters, attended state air-quality events, and conducted interviews with environmental regulators and executives from the waste-to-energy industry. During this research, I encountered many who called the plant a renewable technology that would create much-needed jobs. Meanwhile, opponents balked at claims the project would be "green." The 
incinerator would have had a major impact on the local air due to heavy-metal toxics that land close to their source. But it also would have affected a large regional airshed and released thousands of tons of greenhouse gases (GHGs). Taking a cue from these multi-scalar impacts, the coalition to stop the incinerator both used the medium of air to trouble insider/outsider dichotomies and valued an uneven distribution of power, letting youth from the frontline community lead. Participants, in other words, built a flexible alliance-and they utilized its flexibility. Sometimes it was advantageous for participants to draw symbolic lessons from the materiality of atmospheric connection and call the incinerator "everyone's problem." Sometimes it was necessary to build frameworks that recognized the project's tangible impacts on local people. In more than one way, the atmosphere became a model for distributing authority among disparate members of the group. In fact, the same actors frequently used the same concept to make conflicting arguments about who could claim the issue as their own, invoking the air to flex the problem's boundaries.

In the process of tracking these maneuvers, I argue that activists used the atmosphere to define a problem-space with pliant parameters of authority and vulnerability. Their efforts show that the atmosphere's propensity to fluctuate is not just good to think (Choy and Zee 2015, 212) but also good to put to work-especially among actors jockeying to control the air we breathe. By problem-space, I mean an argument about the boundaries of a problem and who its victims and culprits are (cf. Scott 2004). Who will bear the burdens of something like the Fairfield Project? Who seems to be at fault? Who can (and can't) speak on it with authority? Scholars of environmental justice have long studied pluralistic campaigns that cross lines of place, race, class, and expertise (Allen 2003; Checker 2002, 2004; Brown 2007), but problem-spaces train our eyes on something else. To track a problem-space is to interrogate what constitutes a space of environmental injustice to begin with, and to acknowledge that "the community" of impact is a working category.

More nuanced than scale and less structured than network (two spatial concepts often used to think about these plural coalitions) problem-spaces have size, shape, and direction. They're cloud-like. And though ephemeral, they have borders that mark them off within a medium. To define a pliant problem-space is to frame a problem in such a way that its borders can move according to circumstance, like when Jack said the air was "everyone's" after being charged with meddling. When actors like Jack ply problem-spaces, they shift the middle of a matter of concern. They remap power, care, and blame around a core that better suits their needs. Jack explained the value of this pliancy when confessing the challenges of organizing in the twilight of the factory form, whose disintegration has brought some "very pragmatic problems." *

${ }_{3}^{3}$ David Scott also develops the idea of a problem-space in his work on postcoloniality. For Scott, a problemspace describes a historically contingent "ensemble of questions and answers" with both conceptual and ideological stakes $(2004,4)$. It is at once a discursive arena and-important for this paper-a field of intervention where the kinds of questions worth asking and answers worth having are delimited by the conventions of any given "language-game" $(2004,4)$.

"The factory form is at least in its twilight as a space of solidarity for Baltimore's former factory workers. As a generalized mode of organization, it may well be in its infancy (Blanchette 2020). 
(How do groups "cohere" without the structure of a job?) Perhaps late industrial politics are shifting from the union hall to the medium of shared airspace. And this is just one way that pliant problem-spaces stand to teach us about organizing after industry.

If the waning of old sociopolitical structures is one defining feature of late industrialism, then Kim Fortun (2014) shows us boundary failure is another. Here, too, we see a challenge retrofitted into an advantage, since problem-spaces work by breaching category schemes. Problem-spaces flout essentialisms in other ways as well: people can ply them in fluid, nonhierarchical ways, or they can maneuver for extra power. As scholars work to map the hybrid alliances that coalesce around climate change (Beck 1999; Howe 2014; Jasanoff and Martello 2004) and environmental health (Checker 2002; Allen 2003; Sze 2006; Vine 2019; Nguyen, this thematic collection), then, I want to underscore that there is nothing innately good or bad about atmospheric coalitions. My goal instead is to show how they have become tactics for governing the boundaries of a problem-space and, sometimes, for shifting the middle of that problem-space. In Baltimore, the transience of atmospheric claims occasionally enabled the campaign-and not necessarily residents of Curtis Bay—to claim to speak for "the community."

\section{Terra Firma}

This distinction matters: not all residents supported the campaign against the Fairfield Project. Some viewed it as an unwelcome intrusion from without. Like Fran. "Frankly," Fran whispered, "somebody's just come along, got a grant, and he's stirring up some trouble." Fran was a 70-yearold white woman whose distaste for the campaign I had gleaned from her comments at neighborhood meetings. We were sitting in two rocking chairs in the library one winter morning in 2015, discussing her childhood in Curtis Bay. At least, that was how our conversation started. But Fran kept swerving away. "I think it's bull. Look, my family's been here for years. I own my house outright. And sure, when I was a kid, there were odors from the factories. But we have none of that now... These guys don't know what they're talking about. [The air in] Curtis Bay is 300 percent better than it was."

I would not count Fran as a participant in the production of a pliant problem-space. She was committed to maintaining boundaries. For Fran-as for many older whites with deep roots in Curtis Bay-it was landedness that fixed one "inside" the incinerator's problem-space, and landedness that authorized one to evaluate its place in the community. These same residents often harbored skepticism, even hostility, toward those who were not of the neighborhood, including those who did not live there, those who did not own their homes, and those who appeared (because they were not white) to be recent transplants from the "inner city." Fran set herself apart from "these guys" by claiming to have "been here," and claimed that rootedness made her aware of long-term atmospheric changes. More than that, it vested her position on the incinerator with more legitimacy than the mysterious "he" who "just" showed up. In this way, Fran maneuvered to make long-term land ownership a prerequisite to any proper judgment of the air, asserting a limited zone of emplaced authority around the Fairfield Project (Reno 2011). 
Fran's remarks resemble a phenomenon Alison Kenner (Forthcoming) describes as "asthmatic attunement," whereby past symptoms teach asthmatics how to calibrate their breath to present atmospheres. Because they know how their lungs respond to certain triggers, how much of a wayward environment they can handle, and how quickly their symptoms progress toward attack, these asthmatics can sometimes tolerate bad air by drawing on accrued experience. Fran likewise insisted she knew best because she had seen Curtis Bay weather worse; she knew its toxic capacity. And Fran was only one of many long-time residents I met who claimed their rootedness as a source of development authority.

For others, too, that insight came from having enough historical experience to compare Curtis Bay today with before the 1980s, when deindustrialization struck south Baltimore. Not long ago, Curtis Bay was a busy manufacturing zone, crowded with smokestacks emitting "all sorts of bad stuff." There used to be ominous clouds—sometimes yellow, sometimes red-that substantiated air (Choy 2011). Explosions, for a time, were not uncommon (Ahmann 2020). Back then, many suspected that the atmosphere was making locals sick. But talk of cancer clusters gradually faded as factories left and crime arrived: drugs, sex work, petty theft, unsavory neighbors ("the Blacks," Fran whispered). Old-timers turned their attention to new problems.

Fran wanted me to know that, because environmental quality in Curtis Bay had demonstrably improved since her childhood, I should be wary of arguments the plant was "going to kill everyone." Instead of taking environmentalists' claims at face value, I should be asking why anyone would say something so outrageous in the first place. "I've gotten very jaded about some of this stuff." For two hours, our conversation wandered in this way: I'd ask a direct question ("When did you first learn about the incinerator?"), Fran would make a vague accusation ("Got his fingers in a lot of pies."), then she'd veer into an unrelated monologue:

A guy comes to the community association, says he wants to grow lavender. That doesn't sound too bad on the surface. He says he's gonna distill it for the oil, teach the kids. But there's just something about him. He's gonna come over from the other side of the tunnel [beyond Curtis Bay]...He's gonna come over and teach the kids, who by the way could care less. Still, if it ties into his program, then he gets all this non-profit money.

For a while during fieldwork, I nodded through these strange asides. They were common when I spoke with long-time residents-particularly those in favor of the Fairfield Project. It took me time to read them as theories about the motives of do-gooders from elsewhere in the city who came in and pitched frivolous initiatives. "What are we going to do with a bunch of lavender oil?" Fran laughed. "We need some steady jobs."

I mention this atmosphere of suspicion because it colored how residents like Fran read incomers like Jack. It also set up considerable obstacles for any initiative with even the appearance of non-local leadership, no matter how benign that initiative was. Many were quick to remind me that Curtis Bay had a history of being exploited. The latest betrayal had been industrial abandonment, when bankrupt companies dissolved their pension funds. The second, for those fool enough to fall for it, would be from groups that came to fill the void. Hence old timers' pervasive distrust of non-profits that flitted in "getting grants" for "silly things." This skepticism, 
too, was born of a privileged attunement: old-timers believed their rootedness in Curtis Bay supplied intuition about what sorts of people were trustworthy and what sorts of people were not. Which is not to say they rejected all outsiders out of hand. Many supported the out-of-state company behind the Fairfield Project. Thirsty for economic development after decades of industrial decline (Figure 2), three community associations opted to back the plant while simultaneously disqualifying "outside agitators" who expressed opposition. Fran, for one, appreciated that developers would be investing in the land. Dorothy, another lifelong resident, wondered why opponents would come to Curtis Bay just to "interfere with progress."

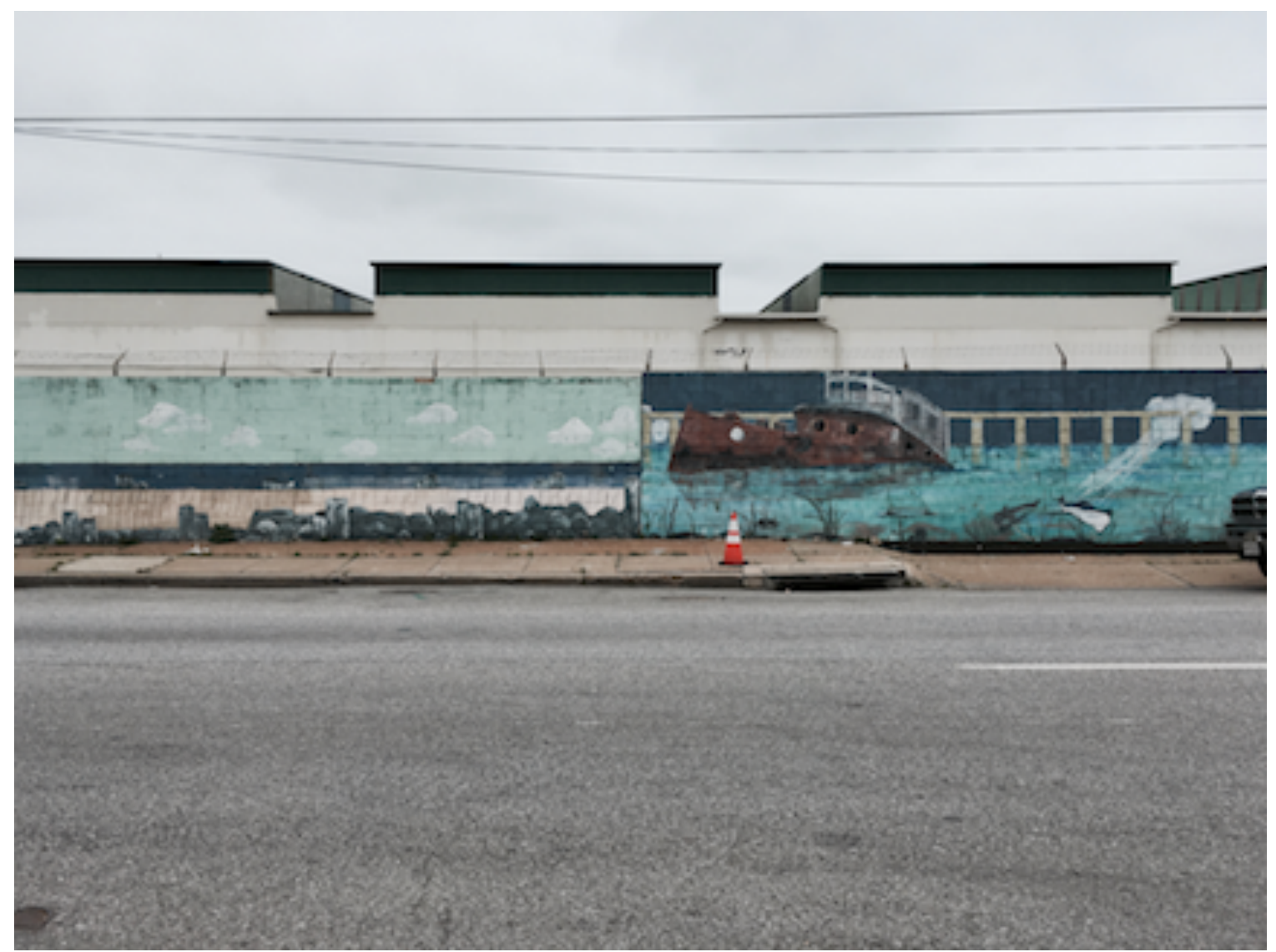

Figure 2: Mural memorializing the once-productive port on the walls of a vacant industrial site in Curtis Bay. Photo by the author, 2016.

Thinkers of the atmosphere would argue there is nothing contextual about these dynamics. They give shape to the air, affecting the pace and direction of late industrial politics. Attuning to the atmosphere, as Kathleen Stewart puts it, means grasping at "palpable and sensory" encounters with ambient things, from particulates to public feelings (2011, 445). Fran's comments point toward the multiple, layered attunements bound up in belonging here: there is a 
historical and embodied relationship with airborne matter (Shapiro 2015; Calvillo 2018; Kenner Forthcoming), there is a yearning for industrial revival (Ahmann 2019), and there is a learned distrust. These attunements came, in Fran's mind, from her groundedness in the terroir of Curtis Bay. Through land, she claimed a raced, emplaced, and generational form of legitimacy that set her apart from those too young, too new, or too dark to judge the Fairfield Project.

The idea that authority over the air should be vested in those who belong to the land may seem counterintuitive. But it is also a regulatory principle in the United States (Grant, this thematic collection). States like Maryland, for example, lack the authority to police pollutants that breeze across state boundaries, so they regulate polluters that themselves are fixed in place. Underlying this regulatory division of labor is the legal concept of jurisdiction, which concerns who can claim a problem as their own. Jurisdiction fixes a problem-space. So, even though it "didn't matter" to the air, it mattered to state regulators where the Fairfield Project would be rooted. They also cared how locals felt about the plant: guidelines for permit applicants encourage "engaging the local community" ahead of filing papers with the state. Terry, a bureaucrat at the Maryland Department of Environment (MDE), told me regulators look for signs of local support when they vet proposals, and that the incinerator's application "looked good" because it included endorsements from official community groups like Fran's-groups I knew worked hard to maintain control over local development. This was the jurisdictional terrain on which the campaign to stop the incinerator eventually took shape.

The campaign emerged out of the local high school in 2012-three years after the Fairfield Project was proposed, and two years after Fran and others signed on to support it-as part of an after-school group loosely organized around the arts and social justice. The group, called Free Your Voice (FYV), had been founded the previous year by a diverse group of students looking to express themselves. "We sort of fumbled around for a while," a young white resident, Josh, recalled. But a structure concretized after their mentor, a white social worker named Greg, began volunteering with Jack's organization, United Workers, and became acquainted with their work in political education. With their permission, Greg began to organize FYV meetings using a United Workers curriculum that he hoped would cultivate critical thinking and nurture civic participation. The curriculum was designed to provide participants with tools for thinking about their world, but they were not meant to engage with those resources in the abstract. So, four months into FYV meetings during the 2012-13 school year, Greg and 20-odd students began researching issues they could use to put their learning into practice. "There was a lot we considered taking on," one young Black resident, Destiny, explained, but things "clicked" when they learned about the incinerator. By December, the group had agreed to focus on the plant, but much work remained to understand how its emissions might affect them. Complicating matters further, Greg and Jack were not equipped to answer students' questions. They knew a good deal about community organizing but considerably less about environmental regulation.

Students soon began to seek outside support, growing the Fairfield Project's problemspace. Apart from United Workers, their earliest allies included the Chesapeake Climate Action Network (CCAN), Maryland Environmental Health Network, and Environmental Integrity Project. Before long, FYV also garnered support from Sierra Club, Physicians for Social 
Responsibility, Global Alliance for Incinerator Alternatives, Democracy Collaborative, and Jews United for Justice. Some partners saw the incinerator as an opportunity to introduce "equity" into their conversations about climate change. Others viewed it as a chance to challenge the city's cozy relationship with corporations. With the help of their mentors, FYV began to organize this vast collection of interests. And by late 2013, students' modest effort to identify an anchor for their after-school curriculum had ballooned into a massive stop-the-incinerator campaign.

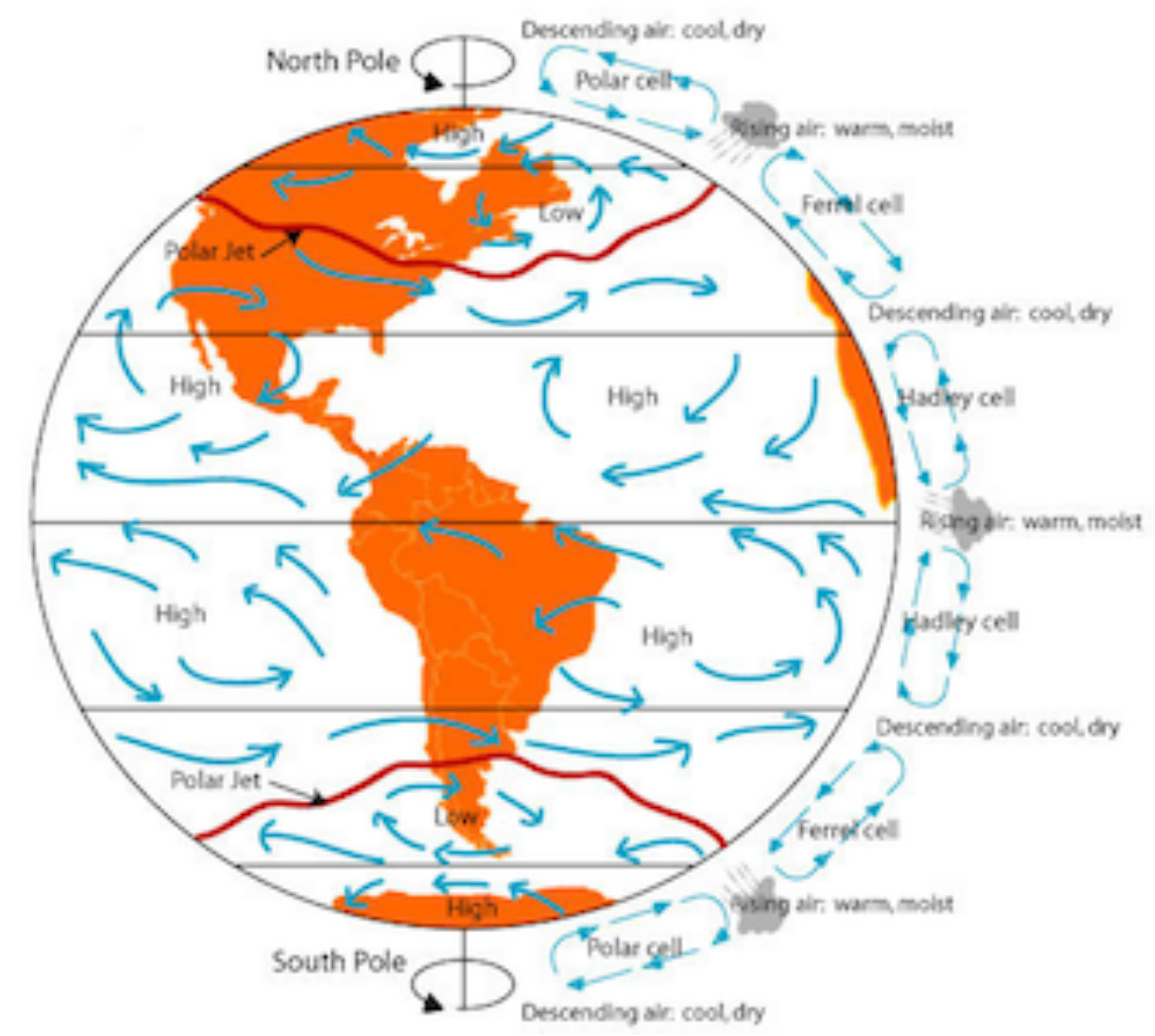

Figure 3: Atmospheric circulation patterns. Image from The Habitable Planet, courtesy of Annenberg Learner.

So, when Fran brushed the campaign off as the brainchild of someone who had "come along" and "got a grant," she was not exactly wrong. United Workers and several other allies did earn funding to support their work in Curtis Bay. But she was not exactly right, either, when she insinuated the campaign had been created from without. As they tell it, local youth themselves decided to fight the incinerator. Neither inside nor outside, neither spearheaded by environmental "experts" nor solely by people rooted in this place, the campaign rested on what Barbara Allen (2003) calls an "uneasy alchemy" of strategic alliances. They could not all claim an emplaced authority like Fran, but as participants in a heterogenous group they did have the benefit of flexibility, which can be helpful when pitted against rigid narratives: here, landed jurisdiction; in Allen's case, "official science" (2003, 6; Epstein 2016). The challenge then becomes 
how best to direct that flexibility. In Curtis Bay, that meant striking a careful balance between local leadership and the capacities of non-local groups. That balance mattered both because residents like Fran detested "carpetbaggers" and because the vague but powerful figure of "the community" has symbolic value for regulators comforted by citizen buy-in.

It was in this context that the atmosphere proved handy for organizers. Both situated and diffuse, uneven and all-encompassing, it offered a way into what Fran and others configured as a narrow problem-space-not by flouting jurisdiction but by reorganizing it, by redrawing the borders of legitimate debate. Conjuring the air allowed different members of the group to claim different forms of belonging to the issue, as well as different degrees. Like the shapeshifting quality Melissa Checker (2002) identifies in "the environment," the atmosphere was usefully capacious. This capaciousness was precisely what allowed the coalition "co-articulate" universal and particular forms of knowledge in a milieu where neither alone would do, to borrow a concept Choy develops to understand translocal environmental politics within a different antiincinerator campaign $(2011,81)$. In what follows, I show how the coalition managed this task by invoking various qualities of the atmosphere, sometimes to expand and sometimes to constrict the boundaries of community, and sometimes to elevate the authority of community while undermining the community associations. That the same concept could serve so many different ends has its roots in the atmosphere's ontology: it is a field of global connectivity linked up by crosscutting winds (Figure 3 ) and composed of differentiated layers.

\section{Everyone's Problem}

The first people to encourage me to think big about the spatiality of exposure were actually statelevel regulators who supported incineration. Take Terry, the bureaucrat from MDE. Terry liked to begin public meetings, as he began our interview, by reminding listeners that Maryland is part of an enormous airshed that stretches north through parts of Canada, west to Ohio, and south through both Carolinas. "I've been doing this a long time," he sighed, directing my attention toward a map behind his desk, "and I've learned most pollutants come here from somewhere else. Our airshed covers 570,000 miles." Terry summoned the airshed whenever MDE was charged with regulatory laxity, as if to say: It's not our fault. We can only regulate where we have jurisdiction. If you want to cast blame, send it across state lines.

The way Terry portrayed it, the airshed posed a challenge to "how most people think about pollution-as a local problem." It was something I should remember whenever I heard farleft environmental groups press for more state regulation. To fixate on the state or local level was, in his mind, to misunderstand the geography of airborne toxics. Recall that Jack had a similar reaction to charges he was "butting in" to debates about incineration. One way to interpret these reactions is as negations of Fran's emplaced authority. Despite their different intentions, both men broadened the incinerator's pool of potential victims and culprits well beyond the local by rendering the atmosphere as a shared, unbounded substrate. This is one of the atmosphere's qualities, its expansiveness, that has attracted scholars to the concept: it offers spatial cues for connecting problems to their distributed causes and effects. But it was also what Terry had in 
mind when he blamed pollution on the airshed, and Jack when he called the incinerator "everyone's problem." Both invoked the air to grow the project's problem-space.

These comments reveal the atmosphere to be a medium of material connection whose spread inspires unifying metaphors. Those metaphors, in turn, can be called upon to free terms like "community" from the territorial confines of a specific neighborhood. Jack went so far as to suggest that virtually anyone could be interpellated as a breather (Choy 2011), though most people made more modest claims. Consider Jeff, a middle-aged white man who lived near the Fairfield site but across the county line. He was fiercely opposed to the incinerator. Jeff called the project a "nuisance" and complained it would let off "bad air" that would trespass into surrounding jurisdictions. Still, he felt powerless to intervene: "It's a city project, so no one cares what the county has to say." Fortun argues that this "transboundary migration" - this toxic seepage-is a key feature of late industrialism, but one the US regulatory system is ill-equipped to manage $(2014,313)$. By definition, jurisdiction discounts "all that escapes" (Cooper 2018). Like Terry, Jeff was infuriated that his air quality would be decided by a government with no responsibility to represent his interests, and he complained his representatives had been fighting the plant to no effect. The atmosphere's reach thus stood in contrast to fixed borders that left Jeff paralyzed. It didn't matter that he lived closer to the Fairfield site than most Baltimoreans: municipal boundaries undercut his claims.

Jeff may have been voiceless before the City Council, but the coalition figured him as part of "the community." When I asked who she meant by the term, Destiny (a resident) counted those who would be "impacted" by the project. That included nearby breathers, like Jeff, and even part-time breathers, like teachers who spent eight hours a day in Curtis Bay. Greg (then a part-time breather) agreed that the pool of potential victims exceeded the area's six-square miles. To vest "any one neighborhood" with exclusive jurisdiction over a project that implicated many others was, in his opinion, "strange...If you think about the community as those who share this air, then it' $d$ be much bigger than Curtis Bay." Gestures like these carved out a legitimate role for non-resident allies to play in the fight. While not necessarily disputing that the plant was a local matter, they drew on the imagery of a vast and undomesticated atmosphere to contend it would be a mistake to assume authority came wholly from location. Put differently, truths about the atmosphere's concrete form informed metaphors of distribution that held up an expansive power-sharing model. No longer "outside" the project's sphere of influence, non-residents like Jeff could stake a rightful claim.

Sometimes the campaign drew the boundaries of the problem even farther, joining the atmosphere with other symbolic systems to describe a universal space of human concern. This was the effect of Destiny's frequent invocation of her "human right to breathe clean air" (Figure 4), a claim connecting her to a worldwide community of rights-bearing persons. With this phrase, Destiny drew a metaphorical equivalence between the reach of the atmosphere and the aspirationally inclusive category of the human, making a point about both along the way.s Recall

s I say aspirationally because, as Sylvia Wynter (2003) and others show, the category of the human has always been exclusive. 
Fran's bigotry: Destiny knew her full humanity was not a given to all residents of Curtis Bay.

For the same reason, even when not invoking rights, Destiny often told listeners that they were "all breathing the same toxic air." She told me these pleas were designed to chip away at the boundaries many locals put up to keep out "meddlers" and to smooth over Curtis Bay's tense race relations. Destiny understood that older whites did not tend to see Black youth as having a legitimate stake in community life, believing most lived in subsidized housing. At neighborhood meetings, these same residents would lean in and tell me Destiny should not be allowed to speak because she did not pay dues to their association. Among themselves, FYV called these assumptions racist, but in public they typically emphasized the atmosphere's indiscriminate effects. "If we want to unite people across color lines," Destiny argued, "we need to realize we're all in this air together." Checker has showcased the discursive power of these homogenizing claims: "by casting the environment as colorblind," activists can make strategic appeals to "interracial harmony" that tend, for better or worse, to be more palatable to certain listeners (2002, 101). This was not a decision Destiny always made, but it was a figurative language she slipped into when speaking to old-timers like Fran and one she characterized as a frustrating but ultimately worthwhile endeavor to build consensus around the campaign.

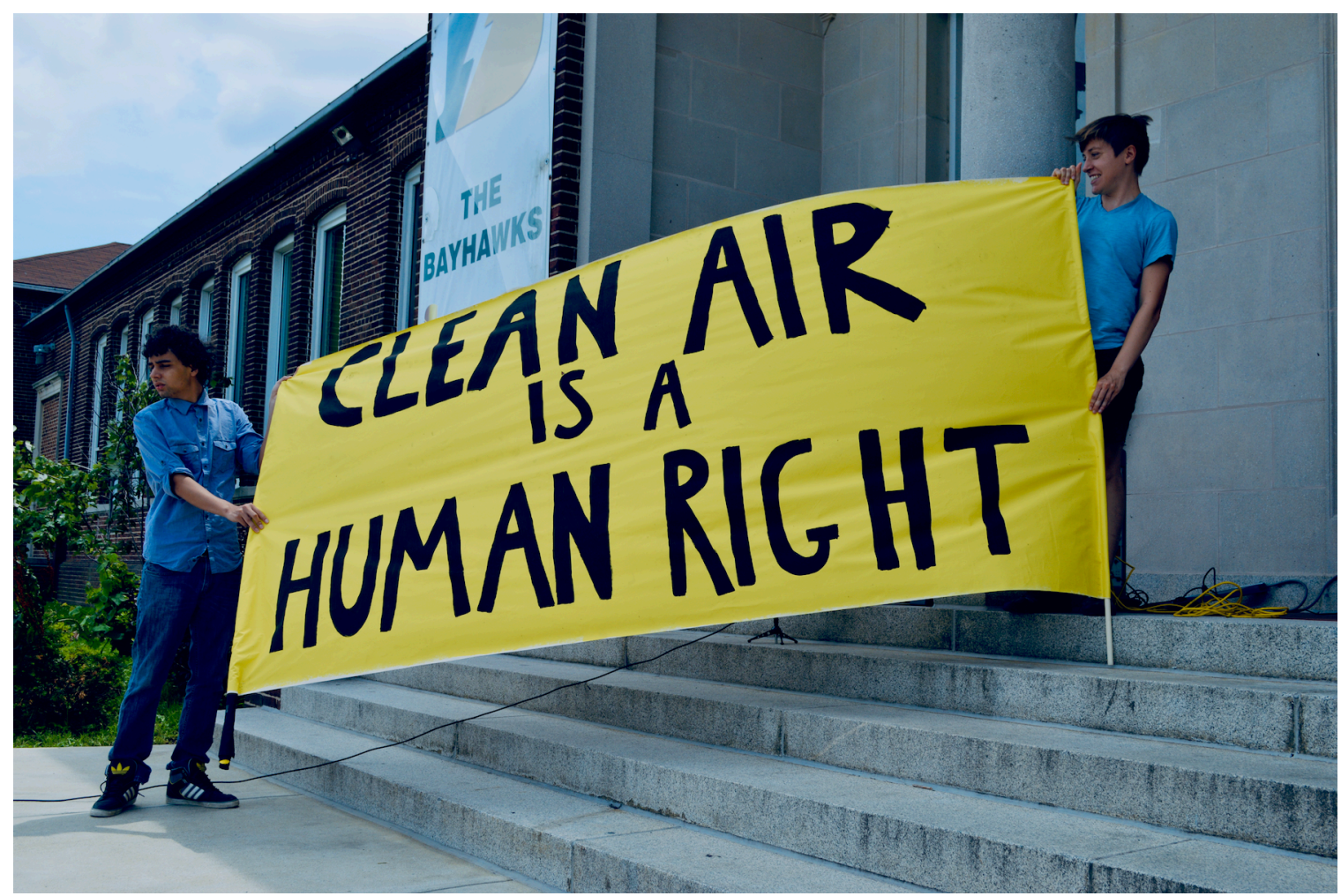

Figure 4: Students hold "Clean Air Is A Human Right" banner at a campaign press conference. Photo courtesy of the United Workers Media Team, 2014. 
Then there were invocations of the atmosphere that exceeded even Destiny's petition to a shared humanity. It was not rare, for example, for activists to call the incinerator a planetary problem, or even to let it stand in synecdochally for all contributors to global climate change. This, too, was a metaphorical move based on material realities about the aggregate effect of GHGs. And it was intended to counter the company's assertion that incineration should be counted as "green" energy, because by diverting trash from landfills it would reduce atmospheric concentrations of methane. In her public overtures, Destiny disputed this idea, telling audiences the Fairfield Project had been permitted to "emit more than two million tons of GHGs per year." At a national climate rally in DC, she called these emissions a "threat to our lives and the future of our planet," enjoining listeners to make themselves heard in Maryland: "Tell our governor [to] stop incineration." It was just one of many instances when the campaign invited non-Marylanders to lobby against state policies with climate consequences by including them within a growing model of the project's scope of impact-one so inclusive that all subjects on earth could conceivably claim a right to speak. More than once, FYV invited national partner organizations to testify in front of the Maryland legislature against waste-to-energy subsidies. They also collected signatures and video testimonies directed at MDE from across the midAtlantic, marshalling them as evidence that "the community" opposed the incinerator.

The campaign's persistent efforts to connect the Fairfield Project to a changing climate can be understood, in part, as a deployment of what Howe (2014) calls ecoauthority. In contrast to an authority, like Fran's, that alleged to know better by being here and looking back, these comments described an everywhere in imminent danger. There are many forms that ecoauthority might take, and Howe is clear that resident communities, like environmental experts, can claim it. Nevertheless, in this context, ecoauthority most often appeared as a universalizing discourse that siphoned power away from those apparently too inward, and too short-sighted, to appreciate the project's sweeping environmental implications.

Claiming ecoauthority is not the same as invoking a universal human right to breathe clean air, nor as decrying arbitrary boundaries. Nor are these admissions that the air "doesn't care" where someone comes from. But they do all put forth a language of connection drawn from the atmosphere's expansiveness to vest non-residents with the capacity to speak. In Curtis Bay, these maneuvers tugged at the boundaries of the incinerator's problem-space. Moving beyond the neighborhood, they worked alongside other metaphors of inclusion to absorb new victims and lay claims to non-territorial forms of knowledge and authority. Taken together, they demonstrate how much work can be accomplished in the name of protecting "everyone" from a proposal like the Fairfield Project with vague but potentially boundless impacts, and in support of a campaign that claims to represent an equally boundless community.

And yet, not everyone belonging to the coalition was comfortable speaking on behalf of others or claiming the incinerator as a threat to their personal well-being. Nadia, an artist-activist from the other side of town, legitimated her participation by figuring the atmosphere as a medium of shared responsibility. Nadia was a white woman nervous about "benefitting from other people's hardships" who had collaborated with students on a performance inspired by the incinerator. The performance earned accolades in the regional art world, which left her "biting 
my fingernails" trying to help without making it "all about me." Nadia viewed herself as a critical practitioner learning to toe the line between contributing her skills and inhabiting the problematic role of "the white woman outsider, the master narrator." Despite this reticence, I once heard Nadia address a crowd at a rally outside MDE. Nadia was there to cheer on FYV, but after a lull she found herself with a bullhorn; Destiny had invited her to speak. "I live in Northeast Baltimore," Nadia reluctantly began, "so the prevailing winds don't come to me from that part of the city. I don't have to worry much about [the incinerator]. And when I look at communities [like Curtis Bay] I think about how unfair that is. I could look at this issue and say it's for other people to fight—for the people directly affected—but really it's on all of us."

Notice the movement in Nadia's speech from outside to inside, unaffected to implicated. It is a movement facilitated by the metaphor of the "prevailing winds," which don't travel to her but are still her responsibility to safeguard. Pressing listeners to think of themselves as part of an atmosphere of neighborly connection-to cultivate what Michael Vine (2019) calls atmospheric care-she argued the incinerator may not be "everyone's problem," but everyone would be culpable if they abandoned Curtis Bay. She did not, then, have to be impacted by the plant to assert belonging to the problem. Like the activists Vine follows in California, she entered into relationships of mutual concern defined by the goal of nurturing more breathable airspace.

By articulating their membership in a diffuse community of prospective victims (like Jack and Jeff), acknowledging shared responsibility for air quality (like Nadia and Terry), and in yet other ways, territorial outsiders wielded the atmosphere's unifying qualities to claim a stake in the incinerator. Their efforts show how specific attributes of the air-its reach, its porosity-can be marshalled to grow a problem-space. In Curtis Bay, a variety of non-local actors called on the air's breadth to share in an authority previously claimed by residents alone. And locals like Destiny used similar language to naturalize what Fran would consider "outside" intrusions into their campaign. Just as STS scholars have drawn on the atmosphere to call for new methodological approaches to the environment, even new objects of study, these examples show that atmospheric faculties can be put to work in concrete and practical ways. Yet, if moving through multiple scales and political forms is a banality for air, it took labor for the coalition to adjust to the fact that "breathing together rarely means breathing the same" (Choy 2016).

\section{Uneven Exposures}

As much as FYV valued building a broad coalition, and as much as members believed there were multiple ways to be legitimately impacted by the plant, they were committed to centering their work in Curtis Bay. For while it was true the Fairfield Project would have planetary effects, it was also true it would have an outsized impact on locals, in part because heavy particulates accumulate in place. Gwen, a doctor from north Baltimore who supported FYV, regularly spoke about heavy-metal "hot spots" to counter arguments (like Terry's) that the airshed's immensity would negate state-level regulation: "For some particles, yes, their spread may be worldwide. But there are others like mercury and lead that fall [near smokestacks] and affect kids locally. And they tend to be sited in low-income and minority neighborhoods." 
Many members of the coalition argued the incinerator was a problem precisely because of these disparities: residents of Curtis Bay were already exposed to industrial pollutants and already burdened with respiratory disease. Such arguments emphasized that airborne toxicswhile undoubtedly diffuse-also concentrate unevenly. I often heard allies refer to Curtis Bay as "overburdened," circulating facts about its stationary emissions ("the highest in the state"), ambient toxicity ("among the country's most polluted ZIP codes"), and life expectancy ("two decades lower" than nearby neighborhoods). Resident-activists like Destiny, too, rarely spoke about the plant without invoking her neighborhood's distinctly "sacrificial" history, shrinking the boundaries of the problem-space back down to Curtis Bay.

These comments point toward another quality of the atmosphere, one just as essential as its breadth: the atmosphere is patchy, fickle, anything but smooth. Rainclouds here one day are gone the next, some places barely register precipitation, and others spend months bathed in spectacular monsoons. Some people breathe cleaner air than others, and most breathe cleaner air than residents of Curtis Bay (Figure 5). It is with these material and embodied differences in mind that Choy (2016), borrowing Marisol de la Cadena's (2018) term, calls the atmosphere an "uncommons," an "unevenly constituted planetary medium for respiration."

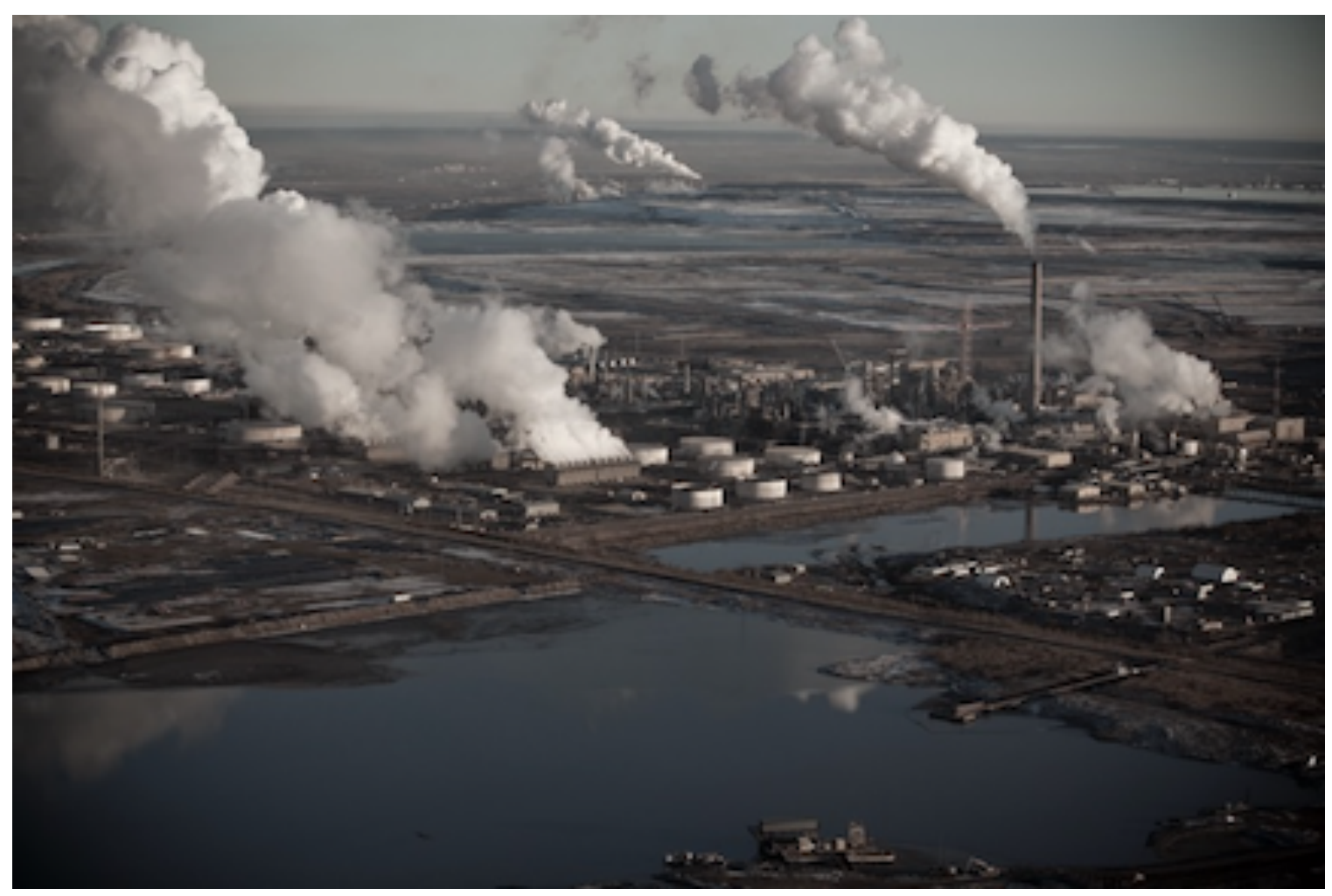

Figure 5: Aerial photo of Curtis Bay, courtesy of Sierra Club. 
STS has a vibrant literature on the uneven geography of exposure that subjects poor and non-white bodies to toxics at disproportionately high degrees (Bullard 1990; Allen 2003; Sze 2006; Agard-Jones 2013; Murphy 2017). Kristen Simmons (2017), drawing on Christina Sharpe (2016), calls this a "normative and necessary violence" in the US settler state-one engineered to give breath to some at others' expense. Environmental justice advocates, too, remind us that not everyone inhales the same air when they breathe. When I call this coalition atmospheric, then, I do not only mean to emphasize its range. Participants summoned shared airspace to authorize an expansive assembly of supporters and seized on concrete air-quality differences to situate those "most affected" at the center of that assembly. The most affected could mean residents, but sometimes it referred specifically to FYV, vesting moral power in local youth. It is not my intent, in pointing this out, to insinuate the group was motivated by ambition. My point is that they took cues from the movement and materiality of air when making claims about who could legitimately care about the Fairfield Project and who, among that larger group, should get to lead. In these examples, we see activists describe the atmosphere as a medium of substantive respiratory difference to strengthen symbolic calls for justice. Those calls, in turn, inform a framework for unevenly distributing authority.

Students claimed that residents should lead, in part, because of their existing body burdens. Whenever Destiny spoke about the incinerator, she would tell listeners that Curtis Bay "is among the most polluted places in the nation. When you live here, you're more likely to suffer from asthma and die of lung cancer." Because "communities like mine have had more than our fair share of pollution," she'd argue, "[we] should be respected when development decisions are made." In calling for community control of development, Destiny echoed Fran's claim to emplaced authority. But instead of landedness-with its particular raced, classed, and generational implications-Destiny cited disparate impact as the source of residents' privileged jurisdiction. It was a characterization that disentangled "the community" from dues-paying neighborhood groups, figuring vulnerable breathers at center of the project's problem-space.

Destiny did not suffer from respiratory disease, but her mother had asthma. So did many of her friends in FYV, and they often brought up their struggles with disordered breathing. Elijah, a young Black member of the group, cited his corporeal experience with atmospheric difference when he attributed his asthma to "all the bad stuff in our air." Adding another smokestack was just going to "hurt us more. That's why we started fighting." Likewise, in the lead up to the 2015 rally at MDE, Josh, another member of FYV, posted a video online about how having asthma informed his opposition to the plant:

A few years ago, I learned about this incinerator planned less than a mile from my school. It'd be pretty bad, because there's already a lot of pollution in my neighborhood...I remember when FYV first came to my class, and they asked students to "raise your hand if you have asthma." Every single person raised their hands...Me, I grew up with asthma. It's a struggle because I have trouble breathing at random moments in the day...and it's just going to get worse with this incinerator. 
Elijah's and Josh's experiences with asthma made them intimately aware of the dangers associated with industrial pollution, authorizing them to call the proposal an unacceptable risk to residents' health and well-being. They knew it would be bad because they already suffered from "the bad stuff in our air." They were drawing on embodied knowledge to prescribe avoidance, to articulate their opposition to the plant as a form of defensive care for their community (Kenner Forthcoming). Among members of FYV, asthma became a shorthand for how the incinerator's material burdens would be felt on a personal level and for suggesting that jurisdiction over the plant should fall to those who, as Destiny put it, would "live and breathe" its impacts: locals, and especially young people (see $n 7$ ). This was one reason they often mentioned the plant's proximity to three schools. And it was why they sometimes characterized old-timers as complacent about pollution—even numb to ambient toxicity (Ahmann 2018a).

Arguments about residents' existing health problems were not only meant to inspire pathos. They circulated in a symbolic economy where claims to disparate impact carried a special weight. When the fight to stop the Fairfield Project began taking shape in Baltimore, it piqued the attention of several "big green" groups hoping to take on "justice" work. Like Destiny's assertion of her "human right to breathe clean air," these appeals drew on the power of two discourses at once to authorize claims against the incinerator. Consider comments from Ben, a white organizer with CCAN. It was 2016 when we met near his office, an hour's drive from Curtis Bay. For two decades, CCAN had lobbied for action on climate change across the mid-Atlantic. It was only recently that they'd committed to "climate justice," Ben explained: "The climate movement was not built on thinking about intersectionality. It was about this enormous global problem," and lately CCAN had been going through "some growing pains... Our membership, like much of the climate movement, started out pretty white. But we've been trying to diversify, which is one reason we help out in Curtis Bay."

Ben's concept of "justice" did not stop with recognizing that environmental burdens have historically been borne by Black, brown, and Indigenous people. It also meant redistributing power to remedy these wrongs-learning how to "help" without grasping for control of the campaign. In this sense, air-quality disparities offered him a model for figuring his role within the coalition: "I want to support [FYV] because they'd bear the brunt of these emissions...I wouldn't want to impose in any way." Sam, a white organizer with Sierra Club, made a similar point when he called the campaign an opportunity "to walk the talk of environmental justice...to live the values we've started to preach." For Sam, as for Ben, "walking the talk" required more than fighting the incinerator; it was also about learning to defer to "the community." Sam first met FYV when he tried to recruit students for a Sierra Club campaign, but when he arrived he realized he should "step back and learn...Sierra Club is used to being in front," he clarified. "It's been uncomfortable, but good, to let them control the messaging."

These comments suggest that, even as the mainstream environmental movement advances a vision of the atmosphere as a shared and fragile medium, its adherents are coming to notice atmospheric difference. This is particularly notable coming from organizations, like Sierra Club, that have long been critiqued for devaluing poor, Indigenous, and racialized groups. Sam, like Ben, acknowledged his organization's exclusionary past and articulated his support of FYV 
as part of a larger effort to redress that past- to use Sierra Club's extensive platform to spotlight a local "equity" issue. For both men, atmospheric thinking meant setting aside a universalist conception of the environment that tacitly privileged their voices. It meant checking their position within a broad coalition and following a power-sharing model that acquiesced to "the most vulnerable," in this case local students. In other words, it meant drawing the Fairfield Project's problem-space in such a way that its center was unmistakably in Curtis Bay. Both organizers emphasized this when they told me authority should be vested, first and foremost, in "frontline communities." Dana, another Sierra Club member, added a generational component when she said that, because the effects of climate change would be unevenly borne by young people, climate justice also meant "following our youth" (see n7).

Students' mentors, too, were committed to letting "the community" lead. Even Jack, while insisting the air was "everyone's problem," felt strongly it was especially a problem in Curtis Bay, where "basics like the right to breathe clean air" are denied to local people. Jack was new to environmental work, but characterized deference to "the people most impacted" as a key principle of grassroots organizing. "When we started [United Workers]," he explained, "we asked ourselves, 'How do you build a social movement, and who's at the forefront of that?' Looking at history, we saw all major social movements were led by the people most impactedthe abolition movement, the feminist movement, the labor movement, on and on-so we took that seriously."

This was a foundational commitment in all of United Workers' campaigns. It was also why Jack and Greg found Fran's accusations (that they would "come along" to "stir up trouble") so upsetting. Under their mentorship, FYV canvassed area streets, held participatory strategy sessions, and worked hard to involve neighbors. This made for a messy and laborious process, but one Greg considered "right" because it put the group's commitments into action by building local power. As he'd joke when things felt especially chaotic: "If we didn't care about this coming from the community, don't you think we'd do things differently? This is the right thing to do, but it's hardly the most efficient way to fight an incinerator."

Just because non-resident supporters agreed on the importance of deferring to the community does not mean power-sharing was always smooth. Recall Sam's "discomfort" and Greg's acknowledgment that deference was "inefficient." Frictions abounded in the campaign. Sometimes they were paltry and interpersonal, and sometimes they reflected serious abuses of power. ${ }^{\cdot}$ But most often they arose when a member of the coalition acted out of step by failing to honor the center of the problem-space. When, for instance, it seemed non-resident allies were working together without first routing their ideas through FYV, group members called it a "red flag." They might mean well, figured Elijah, but "not listening to people who'd be breathing in this stuff is how we got the incinerator in the first place." Likewise, at public speaking engagements, FYV was intentional about limiting non-residents' voices. "We've got to think

' As this article went to press, several present and former organizers with United Workers, as well as campaign allies, raised public allegations against the staff member I refer to as "Jack." This is not the space to air the allegations, but at the very least they serve as a reminder that the politics of deference and authority are just as fraught within as between activist organizations. 
about the optics," Greg once said. "The ask has got to come from Curtis Bay." In these cases, atmospheric difference served as a tool for reining in wayward actors, unevenly distributing authority, and negotiating the politics of representation.

What manifests in these examples is an effort to pin air down, to acknowledge its materiality and track how it accumulates in place. We also see a variety of actors with different backgrounds and commitments turn that materiality into metaphors of difference. Those metaphors then inform a power-sharing model wherein those who breathe polluted air secure leadership roles in the campaign. Whether concerned about persistent health disparities, devoted to climate justice, or inspired by the moral authority of youth, participants invoked the atmosphere's uneven effects when vesting FYV with control-even while using different atmospheric metaphors to articulate non-residents' right to have a say. In this sense, the atmosphere offered them a spatial guide for figuring their roles within a capacious community of concern: some were supporters, others leaders; some set the agenda, others fell in line. It allowed them to flexibly deploy markers like local and global, us and them, in and out, so the boundaries of community could spread out, drift, and contract. It was through this flexibility that jurisdiction over the Fairfield Project gradually came to rest with the campaign.

\section{Shifting the Middle}

In March 2016, Destiny claimed "victory" on behalf of Curtis Bay. MDE had acquiesced and pulled the incinerator's permits-a move journalists called a "win for the community." Fran and others grumbled at this attribution. It served as further confirmation of her suspicion that outsiders could come along and claim the region as their own, turning her misfortune into their opportunity. It didn't help that Destiny was soon awarded the Goldman Environmental Prize, along with $\$ 175,000$ in cash. "Doing what?" Fran asked. "Lying and protesting and stealing jobs?" She was incensed. "Where were they when we did our review?" But most coverage of the Fairfield Project by then did not mention there had ever been local support. And when members of FYV did acknowledge it, they managed to portray the community associations as out of touch with popular sentiments. Indeed, by 2016, it was not only members of the coalition, but MDE's own leaders who figured FYV as the rightful representatives of the community.

To suggest that FYV's position within an uneven geography of exposure bestowed this authority upon them would be to miss the fact that it was an achievement. It took work to expand, move, and constrict the boundaries of the Fairfield Project until they circled around this group. This is what I mean when I say the campaign managed to shift the middle. They claimed control over the project's problem-space. They replaced the community associations as the arbiters of local development, and they did it through a complex but ultimately successful series of atmospheric moves: air pollution is everyone's problem, air pollution is particularly our problem, we all need to take care of the atmosphere, supporters need to follow the lead of local youth. Between insisting the air was "everyone's," worrying about toxic trespass, claiming a universal right to breathe clean air, and cultivating atmospheric care-between pointing out disparate impact, following the "most vulnerable," negotiating leadership, and practicing asthmatic 
attunement-the problem found itself a different core. I do not mean to suggest that all these moves were painstakingly orchestrated in advance, and certainly not that they were disingenuous. What makes this group an atmospheric coalition is that they took advantage of the multiple, even contradictory qualities of the atmosphere to maneuver.

The crucial take-away here is that the atmosphere has capacities that can be directed toward a variety of ends; it has a built-in multiplicity. This multiplicity is precisely what has appealed to scholars seeking to craft a language that can address planetary problems without losing their differential effects (Choy 2011; Choy and Zee 2015; Masco 2015; Kenner Forthcoming; Vine 2019). It's also what makes the atmosphere a fruitful foil for old industrial dreams of order (Fortun 2014). But atmospheric thinking transcends theory. It is, as this case suggests, an eminently practical discourse for governing the boundaries of a problem-space and shifting them as needed. And it is already ubiquitous: atmospheric coalitions drive movements for climate justice, and they can be found in late industrial contexts where people are building alliances that-like emissions-transcend boundaries.

If we hope to do justice to the everyday praxis of these movements, we need a vocabulary up to the task. Thinking in terms of pliant problem-spaces may get us close, because it means beginning from the recognition that categories-in-action are porous, ephemeral, atmospheric things. In fact, thinking in terms of pliant problem-spaces may help us understand coalition work around issues that are not strictly "atmospheric," from wildfires and water pollution to public health and racial justice. Atmospheric coalitions are not alone in their ability to shape and reshape matters of concern, nor to articulate knowledge across scales (Choy 2011; Hecht 2018), but they do offer a fruitful vantage point for grasping how this praxis works because the atmosphere is radically unmoored. Such groups therefore throw the paradoxes of problemspacing into sharp relief. For the coalition to stop the incinerator and others like it, the atmosphere set up a space of environmental concern where one could map relations of care and blame.' It provided a model for both sharing and holding power in a middle-for distributing authority. But this middle could dissipate, drift, cloud up, precipitate. It could be both everywhere and especially here. Or it could elevate an "outsider" like Jack at Fran's expense. Even those scholars already attuned to the atmosphere's conceptual affordances may find, in attending to its hazy tactical life, it's even stranger in practice than it is in theory.

\footnotetext{
"And, arguably, a "time" of environmental concern-evident in gestures toward the moral authority of youth and old-timers' relative complacency. I have written elsewhere about the effects of historical and generational time on local perceptions of the Fairfield Project (Ahmann 2018a, 2018b), but more remains to be done to sketch the temporal dimensions of problem-spacing in coalition work. I thank a reviewer for this observation. Readers interested in thinking more about this can also consult Scott's writing on postcolonial theory, which highlights the historical contingency of any given problem-space (2004; see n3).
} 


\section{Author Biography}

Chloe Ahmann is an Assistant Professor of in the Department of Anthropology at Cornell. Her work is set in Baltimore, and considers what efforts to think and enact environmental futures look like from the sedimented space of late industrialism. For more information and links to recent publications, see www.chloeahmann.com.

\section{Acknowledgements}

Most of the good ideas here came out of quick-talking conversations with Blake Smith; thank you for stepping into a mess of associations and helping me find the argument. Thanks are due, too, to Alison Kenner, Kim Fortun, and Victor Kessler for their feedback on early versions of this paper; to Crystal Hall for thinking with me at the end; to two incisive reviewers for pushing me on the central analytics; to Daniel Kleinman and, especially, Katie Vann for weeding out the slippage that remained; and, of course, to my interlocutors in Baltimore.

\section{References}

Agard-Jones, Vanessa. 2013. "Bodies in the System." Small Axe 17(3):182-92.

Ahmann. 2018a. "It's exhausting to create an event out of nothing': Slow Violence and the Manipulation of Time." Cultural Anthropology 33(1):142-71.

2018b. "Cumulative Effects: Reckoning Risk on Baltimore's Toxic Periphery." PhD Dissertation, George Washington University.

--------. 2019. "Waste to Energy: Garbage Prospects and Subjunctive Politics in Late-industrial Baltimore." American Ethnologist 46(3):328-42.

-------. $2020 . \quad$ "Toxic Disavowal." Somatosphere, January 17. http: / / somatosphere.net/2020/toxic-disavowal.html/.

Allen, Barbara. 2003. Uneasy Alchemy: Citizens and Experts in Louisiana's Chemical Corridor Disputes. Cambridge: MIT Press.

Beck, Ulrich. 1999. World Risk Society. Cambridge: Polity.

Blanchette, Alex. 2019. "Living Waste and the Labor of Toxic Health on American Factory Farms." Medical Anthropology Quarterly 33(1):80-100.

------. 2020. Porkopolis: American Animality, Standardized Life, and the Factory Form. Durham: Duke University Press.

Brown, Phil. 2007. Toxic Exposures: Contested Illnesses and the Environmental Health Movement. New York: Columbia University Press.

Bullard, Robert. 1990. Dumping in Dixie: Race, Class, and Environmental Quality. Boulder: Westview Press.

Calvillo, Nerea. 2018. "Political Airs: From Monitoring to Attuned Sensing Air Pollution." Social Studies of Science 48(3):372-88.

Checker, Melissa. 2002. "'It's In the Air': Redefining the Environment as a New Metaphor for Old Social Justice Struggles." Human Organization 61(1):94-105. 
2004. "We All Have Identity at the Table': Negotiating Difference in a Southern African American Environmental Justice Network." Identities 11(2):171-94.

Choy, Timothy. 2011. Ecologies of Comparison: An Ethnography of Endangerment in Hong Kong. Durham: Duke University Press.

--------. 2016. “Distribution." Fieldsights, Cultural Anthropology, January 21. https: / / culanth.org / fieldsights / distribution.

Choy, Timothy and Jerry Zee. 2015. "Condition—Suspension." Cultural Anthropology 30(2):21023.

Cooper, Jessica. 2018. "Unruly Affects: Attempts at Control and All That Escapes from an American Mental Health Court." Cultural Anthropology 33(1):85-108.

de la Cadena, Marisol. 2018. "Uncommons." Fieldsights, Cultural Anthropology, March 29. https: / / culanth.org/ fieldsights/ uncommons.

Epstein, Steven. 2016. "The Politics of Health Mobilization in the United States: The Promise and Pitfalls of 'Disease Constituencies.'” Social Science and Medicine 165:246-54.

Fortun, Kim. 2014. "From Latour to Late Industrialism." HAU 4(1):309-29.

Grant, Sonia. 2020. "Aggregate Airs: Atmospheres of Oil and Gas in the Greater Chaco." Engaging Science, Technology, and Society 6:534-554.

Hecht, Gabrielle. 2018. "Interscalar Vehicles for an African Anthropocene: On Waste, Temporality, and Violence." Cultural Anthropology 33(1):109-41.

Howe, Cymene. 2014. "Anthropocentric Ecoauthority: The Winds of Oaxaca." Anthropological Quarterly 87(2):381-404.

--------. 2015. “Life Above Earth: An Introduction." Cultural Anthropology 30(2):203-09.

Jasanoff, Sheila and Marybeth Martello. 2004. Earthly Politics: Local and Global in Environmental Governance. Cambridge: MIT Press.

Kenner, Alison. Forthcoming. "Emplaced Care and Atmospheric Politics in Unbreathable Worlds." Environment and Planning C: Politics and Space.

Masco, Joseph. 2015. “The Age of Fallout." History of the Present 5(2):137-68.

McCormack, Derek. 2008. "Engineering Affective Atmospheres on the Moving Geographies of the 1897 Andrée Expedition." Cultural Geographies 15(4):413-30.

Murphy, Michelle. 2017. "Alterlife and Decolonial Chemical Relations." Cultural Anthropology 32(4):494-503.

Nguyen, Victoria. 2020. "Breathless in Beijing: Aerial Attunements and China's New Respiratory Publics." Engaging Science, Technology, and Society 6:439-461.

Reno, Joshua. 2011. "Beyond Risk: Emplacement and the Production of Environmental Evidence." American Ethnologist 38(3):516-30.

Scott, David. 2004. Conscripts of Modernity: The Tragedy of Colonial Enlightenment. Durham: Duke University Press.

Shapiro, Nicholas. 2015. "Attuning to the Chemosphere: Domestic Formaldehyde, Bodily Reasoning, and the Chemical Sublime." Cultural Anthropology 30(3):368-93.

Sharpe, Christina. 2016. In the Wake: On Blackness and Being. Durham: Duke University Press. 
Simmons, Kristen. 2017. “Settler Atmospherics.” Fieldsights, Cultural Anthropology, November 20. https: / / culanth.org / fieldsights / settler-atmospherics.

Sloterdijk, Peter. 2009. Terror from the Air. Cambridge: MIT Press.

Stewart, Kathleen. 2011. "Atmospheric Attunements." Environment and Planning D: Society and Space 29(3):445-53.

Sze, Julie. 2006. Noxious New York: The Racial Politics of Urban Health and Environmental Justice. Cambridge: MIT Press.

Vine, Michael. 2019. "Beyond Touch: Cultivating Caring Atmospheres in Arid America." Journal for the Anthropology of North America 22(1):22-34.

Wynter, Sylvia. 2003. "Unsettling the Coloniality of Being/Power/Truth/Freedom: Towards the Human, After Man, Its Overrepresentation-An Argument." CR: The New Centennial Review 3(3):257-337.

Zee, Jerry. 2020. "Machine Sky: Social and Terrestrial Engineering on a Chinese Weather System." American Anthropologist. 122(1):9-20. 